\title{
Commentary: Are Developmental Skills Acquired Normally in Rett Syndrome?
}

\author{
Jeffrey L. Neul' and Alan K. Percy ${ }^{2 *}$ \\ 'Department of Neuroscience, University of California San Diego, USA \\ ${ }^{2}$ Civitan International Research Center, University of Alabama at Birmingham, USA
}

\section{Article Info}

\section{Article Notes}

Received: 08/04/2016

Accepted: 18/04/2016

\section{Correspondence:}

Dr. Alan Percy

1720 2nd Avenue South, CIRC 329E

Birmingham, AL 35294-0021

Telephone: 205-996-4927

Email: apercy@uab.edu

(c) 2016 Neul JL. This article is distributed under the terms of the Creative Commons Attribution 4.0 International License
Rett syndrome (RTT) is a rare neurodevelopmental disorder affecting females predominantly and associated in $>96 \%$ of individuals with classic RTT with mutations in the methyl-CpGbinding protein 2 (MECP2) gene ${ }^{1}$. The gene product, MECP2, is crucial for the development and maintenance of normal neuronal and glial, particularly astrocytic, function through the activation or suppression of many other genes, for example, $B D N F$, or brainderived neurotrophic factor ${ }^{2}$. RTT occurs in all racial and ethnic groups with an incidence of approximately 1:10,000 live born females $^{3}$, that is, more common than phenylketonuria. From its first recognition, questions were quickly raised regarding the normal acquisition of developmental skills in RTT. The first publications of Rett ${ }^{4}$ and Hagberg et al. ${ }^{5}$ indicated that early development was normal, but already by the creation of diagnostic criteria in 1985 by Hagberg et al. ${ }^{6}$ and later by the CDC's Rett Syndrome Diagnostic Criteria Work Group ${ }^{7}$ the qualifiers "near normal" or "apparently normal" early development were added. These consensus criteria for RTT have been modified more recently based on the identification of the MECP2 mutation type in $1999^{8}$ and further refined in $2010^{\circ}$. As such, the clinical profile has included the phrase 'apparently normal development' to characterize the earliest period in the ontogeny of clinical features in RTT.

The clinical profiles of individuals with RTT have a broad spectrum of severity ranging from significant limitations of gait and fine motor function, inattention, and overall clinical severity to relatively milder involvement with preserved gait, ability to manipulate food or other objects with a modified pincer grasp, and interact using iPads or specialized computer equipment. Atypical forms of RTT have also been identified with either higher or lower degrees of severity including the preservation of some interactive speech in the mildest form or very significant early onset-epilepsy or absence of many developmental skills in the most severe forms. Atypical RTT is associated with $M E C P 2$ mutations in $76 \%{ }^{10}$. This variation in clinical severity is related to a number of different factors including the specific mutation, the degree of X-chromosome inactivation (XCI) favoring the normal X-chromosome, the genetic background, the environment, and the variable distribution of the mutation within the central nervous system. Analyses from large databases have revealed a similar and convincing distribution of clinical severity based on the general type or position of the mutation in $M E C P 2^{10-12}$. However, when looking at two individuals with precisely the same 
mutation, considerable variation in clinical severity may arise. This relates to the other factors noted. Large scale studies of XCI have not occurred. Initial findings suggested only limited XCI variability ${ }^{13}$, but this study contained a relatively small population of individuals with RTT. In an on-going, yet unpublished, study of this phenomenon in more than 200 participants with classic RTT associated with the US RTT Natural History Study, 11\% demonstrated highly skewed X-chromosome inactivation, 26\% moderately skewed, $51 \%$ randomly skewed, and $12 \%$ were uninformative (unpublished data, Friez et al.). Remarkably, the direction of highly skewed XCI was equally represented between the normal and mutated $\mathrm{X}$ chromosome. The overall genetic background (apart from XCI) is deserving of further investigations. The effect of environment and therapeutic interventions on overall health maintenance is remarkable. This is, perhaps, best exemplified by the difference in survival between the original group identified by Rett limiting overall survival to about 25 years and more recent studies of longevity suggesting average survival greater than 50 years ${ }^{14-16}$.

Beginning in the 1990's, formal assessment of development was initiated first by $\operatorname{Kerr}^{17}$ who assessed development in a survey of children with RTT in the United Kingdom and noted evidence of abnormal development in early infancy. This was later extended by Einspieler et al. ${ }^{18}$ and Marschik et al. ${ }^{19}$ using video analysis from fifteen children in the first two years of life with RTT, ten with classic and five with atypical RTT.

In 2014, Neul et al. ${ }^{20}$ described the occurrence of developmental skills in more than 600 individuals with RTT, the largest reported to-date examined directly by teams consisting of a neurologist or geneticist and an experienced clinical coordinator. This allowed for a precise ascertainment of the timing of acquisition of specific developmental skills in this population. Of these, $542 \mathrm{had}$ classic RTT and 96 had atypical or variant forms of RTT, 50 with higher functioning and 46 with lower functioning than seen in classic RTT. Although early developmental skills such as sitting, reaching for an object, or early speech are often acquired, the timing of this acquisition is beyond the normal age where this is accepted as normal in most individuals with classic RTT. This was particularly true for skills expected to be acquired after six months of age. Overall, the acquisition of gross motor and receptive language skills is superior to fine motor and expressive language. For the early skills, sitting, reaching for an object, fixing and following, and social smile, approximately $20 \%$ acquired the first three on time whereas the fourth skill was acquired on time by about $50 \%$. The more complex motor and communication skill such as using utensils or multiword sentences are generally delayed or absent. Further, greater acquisition of motor or communication skills is associated with reduced clinical severity. These better outcomes are typically related to four specific mutation groups, the common point mutations R133C, R294X, and R306C and the 3' truncations. For atypical RTT, the higher functioning group was slightly better in acquisition of early onset skills whereas the lower functioning group was markedly worse. The pattern of developmental skill acquisition and subsequent loss, particularly those skills acquired in the first six months, and the declining head circumference percentile already in the first six months of life suggests that abnormally deficient MECP2 has an adverse impact very early in post-natal life. It is known that the development of neurons and astrocytes is related to normal levels of MECP2 such that the abnormalities described in the human brain are not unexpected ${ }^{21-23}$.

As we enter a period of increased clinical trial activity in this population, it is important to achieve accurate diagnosis as early as possible. Currently, data from the RTT NHS indicates that the average age of diagnosis is 2.7 years, down from about 4 years in the initial years of the study. Still, to effect a treatment as early as possible, age at diagnosis must be reduced even further. Declining growth rate had been recognized in RTT from the initial studies of Rett and Hagberg with declining percentiles over time for head circumference, weight, and height through early childhood ${ }^{24}$. The first clue is the decline of head circumference percentile which can be seen as early as 1.5 months of life. In addition, early infancy may be marked by inattentiveness or lack of response to the parents and the general realization that the infant is passive or too good. These should be clues to the primary care physician that identification of an underlying mechanism or cause should be investigated, either directly or by referral to an appropriate specialist. Coupling these factors with a closer examination of the abnormal pattern of acquisition of developmental skills adds further evidence for the possible establishment of a definitive diagnosis. The advancement of clinical trials and the possibility of identifying disease modifying or directly curative strategies bring further urgency to this diagnostic challenge. Ultimately, it could lead to the creation of a newborn screening program such as already in existence for so-many inherited disorders such as the previously mentioned phenylketonuria.

\section{References}

1. Amir R, Van den Veyver I, Wan M, Tran C, Francke U, Zoghbi H. Rett syndrome is caused by mutations in X-linked $M E C P 2$, encoding methylCpG-binding protein 2. Nature Genetics. 1999; 23(2): 185-188.

2. Pozzo-Miller L, Pati S, Percy AK. Rett Syndrome: Reaching for Clinical Trials. Neurotherapeutics : the journal of the American Society for Experimental NeuroTherapeutics. 2015; 12(3): 631-640.

3. Laurvick CL, de Klerk N, Bower C, Christodoulou J, Ravine D, Ellaway C, et al. Rett syndrome in Australia: a review of the epidemiology. J Pediatr. 2006; 148(3): 347-352. 
4. Rett A. Uber ein eigenartiges hirnatrophisches Syndrom bei Hyperammonamie im Kindesalter. Wiener medizinische Wochenschrift. 1966 116: 723-726.

5. Hagberg B, Aicardi J, Dias K, Ramos O. A progressive syndrome of autism, dementia, ataxia, and loss of purposeful hand use in girls: Rett's syndrome: report of 35 cases. Annals of Neurology. 1983; 14(4): 471-479.

6. Hagberg B, Goutieres F, Hanefeld F, Rett A, Wilson J. Rett syndrome: criteria for inclusion and exclusion. Brain and Development. 1985; 7: 372-373.

7. Diagnostic criteria for Rett syndrome. The Rett Syndrome Diagnostic Criteria Work Group. Ann Neurol. 1988; 23(4): 425-428.

8. Hagberg B, Hanefeld F, Percy A, Skjeldal O. An update on clinically applicable diagnostic criteria in Rett syndrome. Comments to Rett Syndrome Clinical Criteria Consensus Panel Satellite to European Paediatric Neurology Society Meeting, Baden Baden, Germany, 11 September 2001. Eur J Paediatr Neurol. 2002; 6(5): 293-297.

9. Neul JL, Kaufmann WE, Glaze DG, Christodoulou J, Clarke AJ, BahiBuisson N, et al. Rett Syndrome: Revised Diagnostic Criteria and Nomenclature. Ann Neurol. 201068 (eprint ahead of publication): 944-950.

10. Cuddapah VA, Pillai RB, Shekar KV, Lane JB, Motil KJ, Skinner SA, et al Methyl-CpG-binding protein 2 (MECP2) mutation type is associated with disease severity in Rett syndrome. J Med Genet. 2014; 51(3): 152-158

11. Neul JL, Fang P, Barrish J, Lane J, Caeg E, Smith EO, et al. Specific Mutations in Methyl-CpG-Binding Protein 2 Confer Different Severity in Rett Syndrome. Neurology. 2008; 70(16): 1313-1321.

12. Bebbington A, Anderson A, Ravine D, Fyfe S, Pineda M, de Klerk N, et al. Investigating genotype-phenotype relationships in Rett syndrome using an international data set. Neurology. 2008; 70(11): 868-875.

13. Amir R, Van den Veyver I, Schultz R, Malicki D, Tran C, Dahle E, et al. Influence of mutation type and $\mathrm{X}$ chromosome inactivation on Rett syndrome phenotypes. Ann Neurol. 2000; 47: 670-679.
14. Freilinger M, Bebbington A, Lanator I, De Klerk N, Dunkler D, Seidl R, et al. Survival with Rett syndrome: comparing Rett's original sample with data from the Australian Rett Syndrome Database. Dev Med Child Neurol. 2010; 52(10): 962-965.

15. Kirby RS, Lane JB, Childers J, Skinner SA, Annese F, Barrish JO, et al. Longevity in Rett syndrome: analysis of the North American Database. J Pediatr. 2010; 156(1): 135-138

16. Tarquinio DC, Hou W, Neul JL, Kaufmann WE, Glaze DG, Motil KJ, et al. The Changing Face of Survival in Rett Syndrome and MECP2-Related Disorders. Pediatr Neurol. 2015.

17. Kerr AM. Early clinical signs in the Rett disorder. Neuropediatrics. 1995; 26(2): 67-71.

18. Einspieler C, Kerr AM, Prechtl HF. Is the early development of girls with Rett disorder really normal? Pediatr Res. 2005; 57(5 Pt 1): 696-700.

19. Marschik PB, Kaufmann WE, Sigafoos J, Wolin T, Zhang D, BartlPokorny KD, et al. Changing the perspective on early development of Rett syndrome. Research in developmental disabilities. 2013; 34(4): 1236-1239.

20.Neul JL, Lane JB, Lee HS, Geerts S, Barrish JO, Annese F, et al. Developmental delay in Rett syndrome: data from the natural history study. J Neurodev Disord. 2014; 6(1): 20.

21.Jellinger K, Seitelberger F. Neuropathology of Rett syndrome. American Journal of Medical Genetics. 1986; 24 (Suppl 1): 259-288.

22.Armstrong DD. The neuropathology of Rett syndrome--overview 1994. Neuropediatrics. 1995; 26(2): 100-104.

23.Armstrong DD. Neuropathology of Rett syndrome. J Child Neurol. $2005 ; 20(9): 747-753$.

24. Tarquinio DC, Motil KJ, Hou W, Lee HS, Glaze DG, Skinner SA, et al. Growth failure and outcome in Rett syndrome: Specific growth references. Neurology. 2012; 79(16): 1653-1661. 